\title{
Differential responses to gosling distress calls in parental and non- parental Greylag Geese
}

Alina Loth, 1

Didone Frigerio, 1,2

Kurt Kotrschal, 1,2

Georgine Szipl, 1,3凶

Email georgine.szipl@gmail.com

1 Core Facility KLF for Behaviour and Cognition, University of Vienna, Fischerau 11, 4645 Grünau Im Almtal, Austria

2 Department of Behavioural Biology, University of Vienna, Althanstrasse 14, 1090 Vienna, Austria

3 Department of Cognitive Biology, University of Vienna, Althanstrasse 14, 1090 Vienna, Austria

Received: 11 March 2017 / Accepted: 8 November 2017

\section{Abstract}

The pre-fledging survival of Greylag goslings (Anser anser) is known to be influenced by parenting style and particularly parental vigilance. Visual and acoustic cues may be important in parental vigilance: if vision is blocked, for example in a highly structured habitat, acoustic recognition of the goslings by their parents would be beneficial. We confronted parental and non-parental Greylag Geese with playbacks of gosling distress calls and analyzed their behavioral responses. Parental geese showed a significant increase in their vigilance behavior during and after playbacks while geese without offspring 
showed increased comfort behavior. In a permutated discriminant function analysis, we found no family-specific vocal cues in gosling calls, and potential call familiarity did not have any effect on parental behavioral responses. Vigilance in families was further influenced by the number of goslings and gosling age, with increased vigilance when the number of goslings was high, and when goslings were younger. Parental females were more vigilant than parental males, suggesting differences in parental investment between males and females. We conclude that visual cues may be more important in offspring-related vigilance than calls, which elicited different behavioral responses depending on the social class of the geese.

\section{Zusammenfassung}

Reaktionsunterschiede auf Weinlaute in Grauganspaaren mit und ohne Nachwuchs Das Überleben von Gösseln der Graugans (Anser anser) vor dem Flüggewerden wird bekanntermaßen beeinflusst vom Erziehungsverhalten der Eltern, und im Besonderen von ihrer Wachsamkeit. Visuelle und akustische Hinweise können von Bedeutung sein für die elterliche Wachsamkeit: wenn die Sicht behindert ist, beispielsweise in einem dicht bewachsenen Lebensraum, wäre die akustische Erkennung der Gössel durch die Eltern von Vorteil. Graugänse mit und ohne Nachwuchs wurden mit Weinlauten von Gösseln konfrontiert und ihre Verhaltensantworten wurden analysiert. Graugänse mit Gösseln zeigten einen signifikanten Anstieg in ihrer Wachsamkeit während und nach dem Abspielen der Weinlaute, wohingegen Graugänse ohne Gössel verstärkt Komfortverhalten zeigten. In einer permutierten Diskriminanzfunktionsanalyse fanden wir keine akustischen Hinweise auf Familienzugehörigkeit in den Rufen der Gössel, und eine potentielle Bekanntheit der Rufe hatte keinen Einfluss auf die Verhaltensantworten der Eltern. Die Wachsamkeit in den Familien wurde außerdem von der Anzahl und dem Alter der Gössel beeinflusst, sie waren wachsamer wenn sie mehr und jüngere Gössel hatten. Innerhalb der Familien waren die Weibchen wachsamer als die Männchen, was auf Unterschiede im Aufwand zwischen den Geschlechtern hindeutet. Wir schlussfolgern, dass für die Wachsamkeit in Bezug auf den Nachwuchs visuelle Signale von größerer Bedeutung sein könnten als Rufe, die je nach sozialer Klasse unterschiedliche 
Verhaltensantworten bewirkten.

\section{Keywords}

\section{Greylag Geese}

Anser anser

Distress calls

Vigilance behavior

Parental investment

Acoustic recognition

Communicated by S. Kipper.

\section{Electronic supplementary material}

The online version of this article (https://doi.org/10.1007/s10336-017-1521-0) contains supplementary material, which is available to authorized users.

\section{Introduction}

Parental investment generally supports offspring survival and thereby, parental reproductive success (Trivers 1974). The costs of investment, however, vary in different species or mating systems and also between sexes. Females produce fewer and larger gametes than males and, therefore, have higher costs if the offspring does not survive (Maynard Smith 1977). This asymmetry in reproductive effort is supposed to cause post-mating differences in parental investment between males and females, as females usually invest more in parental care than males (Wade and Shuster 2002).

In birds, parental care can be shared by both sexes at early developmental stages (Ligon 1999). Especially in precocial species, avian parents usually invest in visual and acoustic vigilance behavior to avoid predation and to monitor the social environment. The main trade-off of visual vigilance is with feeding, due to the mutually exclusive nature of having the head up in vigilance and feeding from the ground (Trivers 1974; Lazarus and Inglis 1978; Caraco 1980). One possibility to counteract this trade-off is vocal signals, which are used in a variety of social contexts (Fichtel and Manser 2010), particularly in environments where visibility is limited or when individuals disperse over an 
expanded area and group cohesion needs to be re-established or monitored (Marler 2004; Tibbetts and Dale 2007). Distress calls, for example, can signal a need for parental care and may function to maintain group cohesion, as shown for primates (Pflüger and Fichtel 2012), dolphins (Janik and Slater 1998), and waterfowl (Black 1988). They may function as a call for aid (Chaiken 1992), or they may warn conspecifics in a potentially risky situation (Branch and Freeberg 2012). In parent-offspring interactions, distress calls communicate that a situation is considered stressful or dangerous (Bermant 1963), and often solicits a caregiver's response (Lingle et al. 2012). Between several different mammal and bird species, distress calls show convergent similarities in their frequency modulation (Lingle et al. 2012) depending on the system of parental care and on the associated anti-predator strategies.

Greylag Geese (Anser anser) are social birds engaging in long-time monogamous relationships. Both sexes invest in parental care and family bonds are at the core of the complex social relationships within the flock (Rutschke 1987; Scheiber et al. 2009a, b). Physiological and behavioral synchrony between the pair partners is related to the quality of the pair bond, and pairs which are physiologically synchronized have higher reproductive output (Weiss et al. 2010; Hirschenhauser 2012). Recent observational studies suggest a major role of vigilance in family cohesion and to minimize gosling loss during rearing (Block 2013) (unpublished data). Male parental geese are known to show higher levels of vigilance than their female partners: Black and Owen (1989) showed that for Barnacle Geese (Branta leucopsis) males with offspring spent more time being vigilant $(16 \%)$ than their female partners $(10 \%)$ from autumn to spring, when their gosling were 5-10 months old. Williams et al. (1994) found similar results for Lesser Snow Geese (A. caerulescens caerulescens). When separated from their foster parent, hand-reared goslings of Canada Geese ( $B$. canadensis), Bar-headed Geese (A. indicus), and Greylag Geese display distress calls (Lamprecht 1977; Thoren and Bergmann 1987). These distress calls generally elicit enhanced visual vigilance in parents (Johnsgard 1965; Thoren and Bergmann 1987; Beecher 1988; Sharp et al. 2005), which constrains feeding and thus can be considered energetically costly. Hence, acoustic signals as additional means of maintaining cohesion and communicating domain of danger would contribute to reducing parental surveillance costs.

It was shown that 5-day-old goslings of Canada Geese are able to recognize 
their parents by their calls individually (Cowan 1973) and to discriminate their siblings from unknown ones visually at the age of 6 days (Radesäter 1976). Distinctive features in distress calls and the ability to discriminate them could be highly advantageous for goose parents, since they could respond specifically and forego costs of both permanent visual vigilance or misdirected care in an environment where goslings may get out of visual sight, and thus visual survey is limited, and where other families with goslings of the same age are nearby.

Here, we investigated responses of adult Greylag Geese to gosling distress calls. For this, we exposed parental and non-parental geese to distress calls of goslings. Parental geese were tested with distress calls of their own goslings as well as with distress calls performed by unfamiliar goslings, thereby additionally testing whether parental geese would be able to discriminate between distress calls of own and unfamiliar goslings. Non-parental geese were tested with distress call playbacks of different unfamiliar goslings. We hypothesized that parental geese would in general respond with increased vigilance because goslings in distress could indicate danger for their own goslings. However, if parental geese were able to discriminate their own goslings from unfamiliar goslings by their distress calls, we would expect, despite a general response towards distress calls, stronger responses to calls of their own goslings as to avoid misdirected vigilance. Non-parental geese, on the other hand, were expected to show no or unspecific behavioral responses because being vigilant would not benefit them.

\section{Methods}

\section{Focal animals and study area}

This study was conducted at the Konrad Lorenz Research Station in Grünau im Almtal, Austria. The flock of Greylag Geese was introduced into the valley of the river Alm by Konrad Lorenz in 1973 (Lorenz 1988). At the time of data collection, the flock consisted of 159 free-roaming birds, which were individually marked with coloured leg bands. The flock was well habituated to the presence of humans. Individuals allowed close approaches without showing any behavioral changes or physiological signs of stress (Wascher et al. 2008). Predators such as red foxes (Vulpes vulpes) and eagles (Aquila chrysaetos) cause a yearly loss of up to $10 \%$ of the flock (Hemetsberger 2001), which 
resembles other wild geese populations (Owen 1982; Ebbinge 1985).

The present study was conducted during the breeding season 2013. A total of 24 parental pair-partners (12 pairs with offspring; i.e. 12 males and 12 females, termed focal families) and 16 adult pair-partners (eight pairs; i.e. eight males and eight females, termed focal pairs) without hatched goslings in this breeding season were tested in playback experiments, which were conducted from 5 th June to 7 th July. The number of goslings per family ranged between 1 and 8 immediately after hatching (mean number of goslings per family $\pm \mathrm{SD}$ :

$5.08 \pm 1.71$ ), and between 1 and 4 during the experiment (mean number of goslings per family $\pm \mathrm{SD}: 2.00 \pm 1.21$; Table 1$)$. At the time of the experiment the age of the goslings ranged between 24 and 68 days (mean age \pm SD: $46.83 \pm 11.44)$. The average age of the goslings at the first playback was $46.83 \pm 11.95$ days (SD) and $54.83 \pm 10.31(\mathrm{SD})$ at the second playback. The average age of the goslings at the time of the sound recording was $22.50 \pm 9.55$ days $(\mathrm{SD})$.

\section{Table 1}

Tested Greylag Geese families, with the number of hatched offspring, gosling age in $d$ recording and the playback experiment, and the unfamiliar stimuli used in the playback

\begin{tabular}{|l|l|l|l|l|l|l|}
\hline $\begin{array}{l}\text { Family } \\
\text { number }\end{array}$ & $\begin{array}{l}\text { Family } \\
\text { (mother_father) }\end{array}$ & $\begin{array}{l}\text { Number } \\
\text { of } \\
\text { hatched } \\
\text { goslings }\end{array}$ & $\begin{array}{l}\text { Age of } \\
\text { goslings } \\
\text { during } \\
\text { recording } \\
\text { in days }\end{array}$ & $\begin{array}{l}\text { Age of } \\
\text { goslings } \\
\text { at 1st } \\
\text { playback } \\
\text { in days }\end{array}$ & $\begin{array}{l}\text { Age of } \\
\text { goslings } \\
\text { at 2nd } \\
\text { playback } \\
\text { in days }\end{array}$ & $\begin{array}{l}\text { Un } \\
\text { stin }\end{array}$ \\
\hline 1 & Levi_Plum & 5 & 31 & 61 & 67 & Ler \\
\hline 2 & $\begin{array}{l}\text { Kleine } \\
\text { Hexe_Baycox }\end{array}$ & 4 & 30 & 66 & 68 & Baई \\
\hline 3 & Baggin__Buttercup & 7 & 38 & 49 & 65 & Kle \\
\hline 4 & Ginny_Halas & 1 & 24 & 45 & 53 & Dut \\
\hline 5 & Leviathan_JB & 6 & 29 & 55 & 60 & Lev \\
\hline 6 & Duftspur_Cap & 6 & 20 & 56 & 63 & Jud \\
\hline 7 & Lando_Bacardi & 4 & 29 & 51 & 56 & Du」 \\
\hline 8 & Timber_Murphy & 8 & 19 & 36 & 44 & Gin \\
\hline & & & & & & \\
\hline
\end{tabular}




\begin{tabular}{|l|l|l|l|l|l|l|}
9 & Judith_Tarek & 4 & 21 & 44 & 57 & Tin \\
\hline 10 & Löwenherz_Smoky & 5 & 14 & 36 & 43 & Ing \\
\hline 11 & Erna_Kordula & 6 & 6 & 39 & 42 & Ing \\
\hline 12 & Ingeborg_Idgie & 5 & 9 & 24 & 40 & Ern \\
\hline
\end{tabular}

\section{Sound recordings and preparation of stimuli}

Gosling distress calls were recorded from the 12 focal families (cp. Table 1). The number of calls per family ranged from 12 to 104 (mean \pm SD:

$34.08 \pm 24.20$ ). Recordings were conducted at a distance of approx. $1 \mathrm{~m}$ using a Sennheiser K6 module/ME67 long gun directional microphone (Sennheiser Electronic GmbH \& Co. KG, Wedemark, Germany) and a Marantz PMD-670 digital recorder (D\&M Holdings Inc., Kanagawa, Japan). Recordings had a sampling rate of $48 \mathrm{kHz}$ and a 16-bit amplitude resolution. Only calls with a high signal-to-noise ratio were selected for acoustic analysis and subsequent playback sequence preparations. Distress calls were analyzed using a script in PRAAT (Version 5.3.05), which extracted calls and measured total call duration (ms), minimum, maximum, and mean fundamental frequency ( $f_{0}$; settings: minimum $=75 \mathrm{~Hz}$, maximum $=5500 \mathrm{~Hz}$, time-step $=0.01$; measured in $\mathrm{Hz}$ ), and the time when minimum and maximum $f$ occurred within each call relative to the total length of the call (\%; calculated as the time point divided by the total duration and multiplied by 100). Measured parameters were logged into an output file, and each annotated call was saved as a wav-file. We applied a Hann stop band filter between 0 and $400 \mathrm{~Hz}$ to all wav-files to reduce background noise. Sound pressure levels of filtered sound files were then adjusted using Sound Booth CS4 before creating stimuli for playback sessions.

\section{Experimental setting}

Both mates (male and female) of a family or pair were tested simultaneously. Each family/pair was involved in two sessions, and each session consisted of two trials. Each trial included three conditions: a baseline period before the playback $(20 \mathrm{~s})$ followed by a playback period of $10 \mathrm{~s}$ in which six distress calls with a total duration of $1 \mathrm{~s}$ were presented and a control period after the playback of $20 \mathrm{~s}$. After a recovery period of $10 \mathrm{~s}$, the second trial followed 
(Fig. 1). For families, trials were randomized with respect to familiarity of the distress calls (distress call sequences of own or unknown goslings). Therefore, within one session, families received one familiar and one unfamiliar distress call sequence and pairs received two unfamiliar sequences. Unfamiliar call sequences played to families were selected to match the age of their own goslings [mean age difference of own and unfamiliar goslings $=4.33 \pm 2.71$ (SD)].

\section{Fig. 1}

Setup of playback experiment: Each trial included three conditions: a baseline phase before the playback, the playback, and a control post-playback phase. The two trials of a session were conducted twice with a recovery phase between them

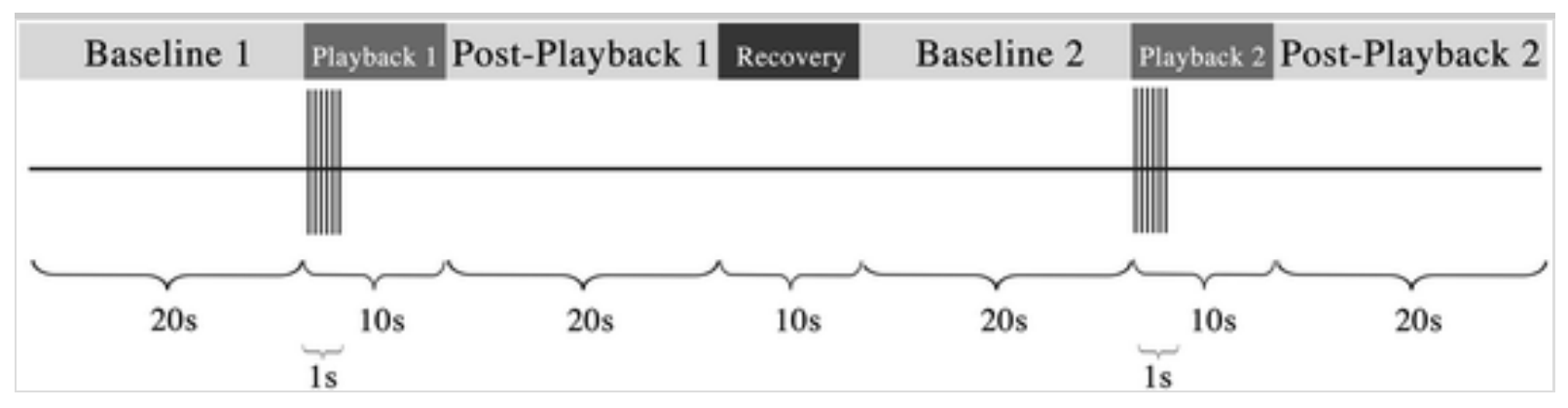

To avoid possible habituation to the playback design, the minimum interval between two consecutive sessions was 3 days. Playback sequences consisted of random samples of distress calls of the goslings of one family and resembled the goslings' natural call rates. The entire experiment was kept in a narrow time frame (a total duration of $110 \mathrm{~s}$ per session) to avoid close proximity to other families (minimum distance $10 \mathrm{~m}$ ) or other disturbances, which would have led to an abortion of the playback (e.g. passing cars).

During the experimental period, all families were monitored on a daily basis to ensure that focal families were never in close contact to each other so that sound recordings of their respective goslings could serve as unfamiliar stimuli in the playback experiment. The distress call sequences were played back as wav-files from a Transcend Digital Music Player (MP870) and a portable loudspeaker (Roadboy 6.5, LD Systems, frequency response: $50 \mathrm{~Hz}-20 \mathrm{kHz}$, Maximum sound pressure: $118 \mathrm{~dB}$, height by width: $300 \times 200 \mathrm{~mm})$. A Sennheiser wireless transmitter/receiver system (evolution wireless G3, ENG 
set ew112-pG3) interconnected the player with the loudspeaker, and enabled the experimenter to start the playbacks without being in close proximity to the speaker and the focal individuals. The loudspeaker was placed at a distance of approx. $2 \mathrm{~m}$ from the focal geese as studies showed that family members usually stay close to each other (Frigerio et al. 2001; Rutschke 1986). The geese are well habituated to human observers and experimental equipment, including the loudspeaker. The geese mostly foraged and rested in the open. To keep the distance to the speaker and the sound pressure level constant, the speaker could not be hidden behind bushes or trees. The playbacks were started when none of the focal geese showed vigilance behavior and continued their previous behavior (e.g. foraging, resting). Sounds were played with sound pressure levels of $63 \mathrm{dBc}$ on average at one meter (Voltcraft SL-100), which resembles natural intensities of gosling distress calls.

\section{Behavioral observations}

Behavioral responses during the sessions of the three conditions of the playback experiment (baseline, playback, post-playback) were videotaped and blind coded by AL using Solomon Coder beta (C) 2013 András Péter). Videos were coded without sound, and thus the coder was blind to the session and the conditions (i.e. the onset of the playback stimuli). Coded behavioral responses included the frequency and the duration of three different stages of vigilance behavior (head low, head up, extreme head up, see Fig. 2) according to the description of Lazarus and Inglis (Lazarus and Inglis 1978), and comfort behavior, e.g. feather shaking and auto-grooming with the beak (Lorenz 1988). For baseline and post-playback conditions, frequency and duration measurements were adjusted to match the shorter playback condition and therefore divided by two (see Fig. 1). 10\% of the videos were re-coded by GS to calculate inter-rater reliability using one-way single measures intra-class correlations (ICC). The ICCs for the frequency and the duration of the three vigilance stages and comfort behavior were excellent and ranged from 0.836 to 0.968 .

\section{Fig. 2}

The three stages of vigilance behavior in Greylag gGeese: head low (low vigilance, on the left), head up (increased vigilance, in the middle), and extreme head up (high vigilance, on the right). Drawing by A. Loth 


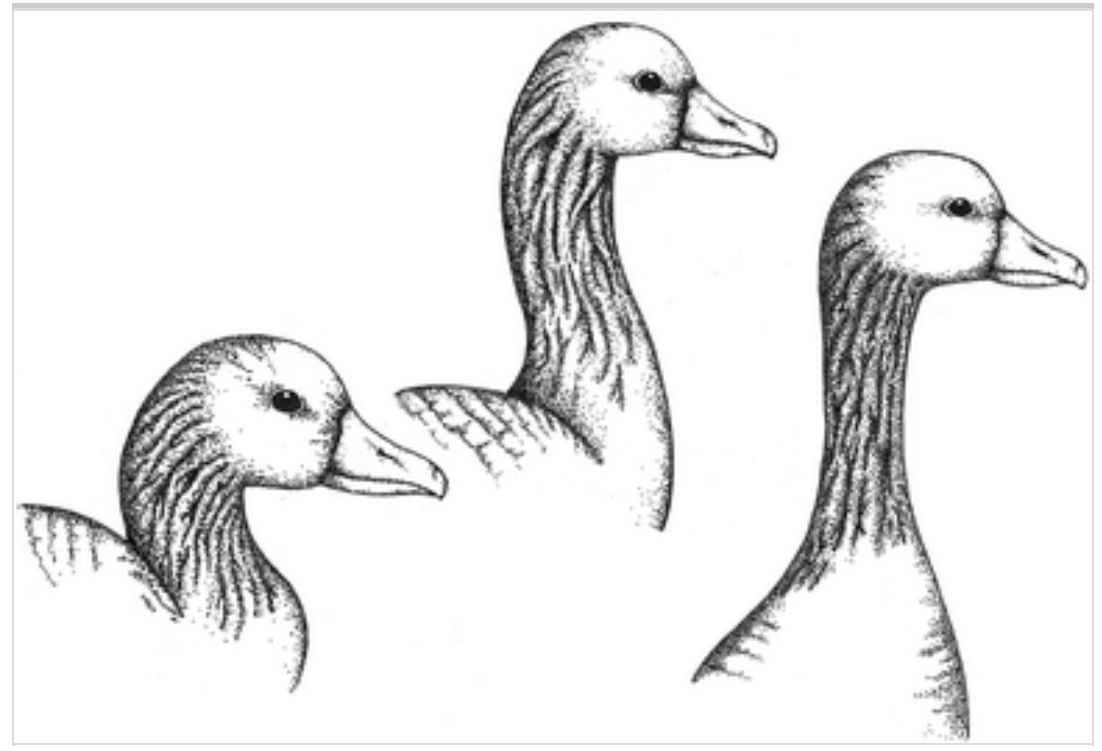

\section{Statistical analysis}

Distress calls

Four hundred and forty-five distress calls of 12 families were then analyzed using nested permutated discriminant function analyses (pDFA) with 100 random selections and 1000 permutations (Mundry and Sommer 2007). Family was used as a test factor. The age of the goslings in days at the time of recording was entered as a control factor to account for the possible age effects. All measured acoustic parameters (call duration, minimum $f_{0}$, maximum $f_{0}$, mean $f_{\mathrm{o}}$, and the time of minimum and maximum $f_{\mathrm{o}}$ in the calls) were entered in the analysis. In addition, non-parametric Spearman rank correlations were calculated to investigate the link between gosling age and the measured acoustic parameters of gosling distress calls.

\section{Behavioral responses}

A principal component analysis (PCA) was conducted for data reduction. Components with eigenvalues greater than 1.0 were extracted and Varimaxrotated. Three principal components (PCs) were extracted which explained $87.58 \%$ of the total variance. The Kaiser-Meyer-Olkin measure of sampling adequacy (KMO) was 0.53 . PC 1 included the duration and the frequency of the high vigilance stage "extreme head up" and explained $38.14 \%$ of the variance (for a visual representation of the vigilance stages, see Fig. 2). PC 2 included the duration and the frequency of comfort behavior and contributed $27.7 \%$ to 
the total variance. The third extracted PC included the duration and frequency of the lower vigilance stage "head up" and explained $21.3 \%$ of the variance (Table 2). Regression scores of the three PCs were extracted, and added plus 1 (PC 1 and 3) or plus 2 (PC 2) to create positive values. Linear mixed models (LMMs) with a normal distribution and an identity link were conducted using each PC separately as response variable. A nested term that included the playback trial (first or second) and the session (one and two) within individuals within each family and/or pair was entered as random effect to account for repeated measures. In addition to random intercepts, random slopes were fitted for playback trial and individuals (Barr et al. 2013). Fixed factors were examined for potential multi-collinearity before conducting LMMs by calculating variance inflation factors using the HighstatLibV6 package (Zuur et al. 2009). None of the fixed factors in either of the models showed collinearity.

\section{Table 2}

Results of the PCA, with behavioral parameters and their loadings on the three PCs derived after Varimax rotation $(\mathrm{KMO}=0.529)$ for families and pairs. Loadings higher than 0.5 are highlighted in bold type

\begin{tabular}{|l|l|l|l|}
\hline \multirow{2}{*}{ Behavioral parameter } & \multicolumn{3}{|l|}{ Principal component } \\
\hline Extreme head up (duration) & $\mathbf{1}$ & $\mathbf{2}$ & $\mathbf{3}$ \\
\hline Extreme head up (frequency) & $\mathbf{0 . 9 5 8}$ & -0.041 & 0.021 \\
\hline Comfort behavior (frequency) & $\mathbf{0 . 9 5 1}$ & -0.030 & 0.152 \\
\hline Comfort behavior (duration) & -0.014 & $\mathbf{0 . 9 2 3}$ & -0.054 \\
\hline Head up (duration) & -0.055 & $\mathbf{0 . 9 0 7}$ & -0.139 \\
\hline Head up (frequency) & -0.052 & -0.133 & $\mathbf{0 . 9 1 5}$ \\
\hline & 0.242 & -0.063 & $\mathbf{0 . 8 8 7}$ \\
\hline
\end{tabular}

AQ1

In a first step, we investigated differences between the responses of families and pairs. For this, the fixed factors condition (baseline, playback, post-playback), sex (males vs. females), group membership (families vs. pairs), and the twoway interactions between condition and group and condition and sex were entered in the full model. Then, we investigated variations in responses within 
each group (families and pairs). For families, the fixed factors condition, familiarity (familiar or unfamiliar distress call sequence), sex, the number of goslings, and their age (in days) were used as fixed factors. Moreover, interactions between condition and familiarity, condition and sex, and sex and familiarity were used. For the pairs, only sex and condition and their two-way interaction were used as fixed factors, as non-parental pairs had no goslings. In a first step, we tested the global model against the null model. If the global model explained variation in the response variable significantly better than the null model, we removed non-significant interactions and report these model results with pairwise comparisons of the main effects. Diagnostic plots were used to assure that model assumptions were met. Statistical analysis was performed in R Version 3.3.3 (R Core Team 2017) using the packages GPA rotation [version 2014.11-1 (Bernaards and Jennrich 2005)], psych [version 1.7.3.21 (Revelle 2017)], lme4 [version 1.1-13 (Bates et al. 2015)], and MuMIn [version 1.15.6 (Barton 2009)]. Boxplots were created in R. The boxes represent the lower and upper quartiles (25th and 75 th percentile), the bold lines in the boxes indicate the median (50th percentile), and the whiskers mark $1.5 *$ interquartile ranges.

\section{Ethical note}

The permission to keep Greylag Geese for scientific purposes according to $§ 16$ of the Austrian Animal Experiments Act (Federal Law Gazette No. 114/2012) was issued by the Austrian Federal Ministry of Science, Research and Economy (BMWFW) under the license number BMWFW-66.006/0011-WF/II/3b/2014. No additional approval was required as the experiments were non-invasive, and therefore, did not fall under the Austrian Animal Experiments Act $§ 2$.

\section{Results}

\section{Distress calls}

Distress calls of goslings were tonal with a mean duration of $140.02 \mathrm{~ms}$ (SD: $63.58 \mathrm{~ms}$ ). Calls showed time-frequency modulations and several harmonics (Fig. 3). fo had an average minimum at $2450.52 \mathrm{~Hz}$ (SD: $263.301 \mathrm{~Hz}$ ). Average maximum $f o$ occurred at $3142.02 \mathrm{~Hz}$ (SD: $505.18 \mathrm{~Hz}$ ), and mean fo was measured at $2813.23 \mathrm{~Hz}$ (SD: $351.76 \mathrm{~Hz}$ ). The calls had their average maximum $f_{0}$ at $47.5 \%$ (SD: $14.26 \%$ ) and the average minimum $f_{0}$ towards the end of the 
calls at $75.34 \%$ (SD: $12.48 \%$ ). The pDFA failed to discriminate gosling calls based on family-specific cues: only 148.74 of the original, cross-validated calls $(N=445)$ were correctly assigned to the families $(p=0.471)$. Neither of the acoustic parameters showed was correlated with the age of the goslings (Table 3), indicating that the acoustic properties of gosling distress calls did not vary with gosling age at the time of recording, which ranged from 6 to 38 days (cp. Table 1).

\section{Fig. 3}

Example of gosling distress calls (spectrogram settings: FFT method, Gaussian window shape, time steps $=1000$, frequency steps $=250$, window length $=0.007$, dynamic range $=50 \mathrm{~dB}$ )

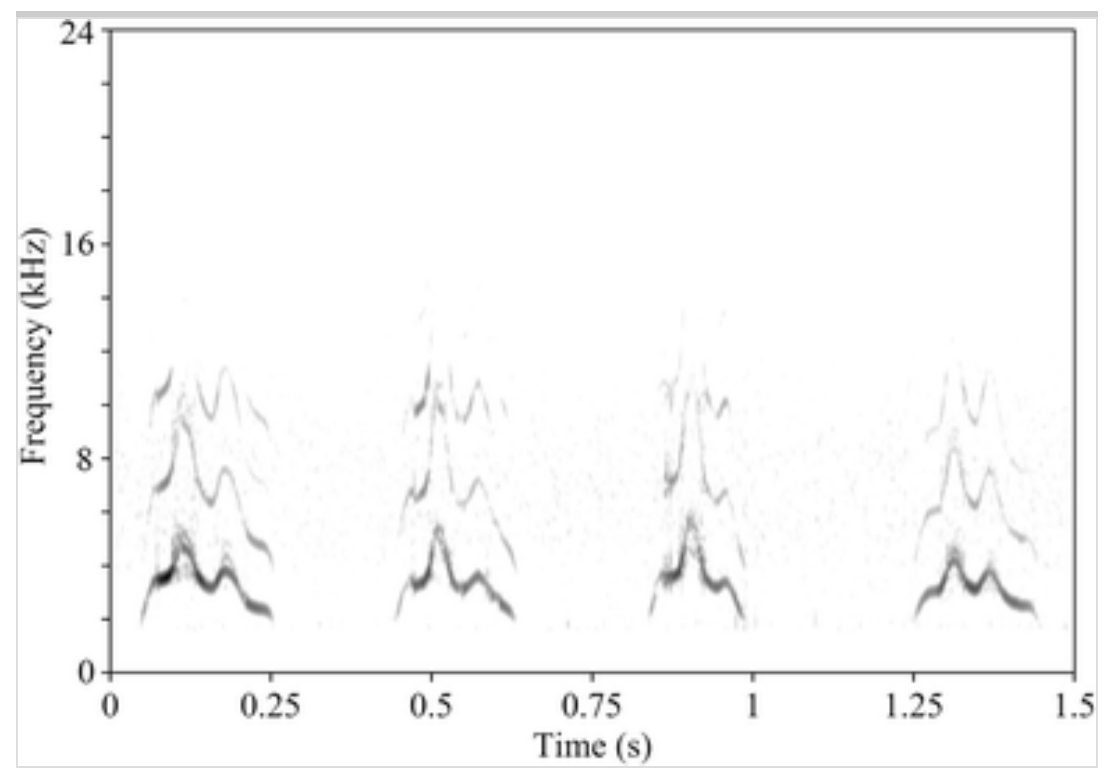

\section{Table 3}

Results of the Spearman rank correlations of gosling age at recording in days and acoustic measures of gosling distress calls of the 12 families $(N)$

\begin{tabular}{|l|l|l|l|}
\hline Acoustic parameter & $\boldsymbol{N}$ & $\boldsymbol{R}$ Should be lower case " $r$ " .... & $\boldsymbol{p}$ \\
\hline Call duration $(\mathrm{ms})$ & 12 & 0.081 & 0.8035 \\
\hline Minimum $f_{\mathrm{O}}(\mathrm{Hz})$ & 12 & -0.119 & 0.7124 \\
\hline Time of minimum $f_{0}(\%)$ & 12 & 0.193 & 0.5486 \\
\hline Maximum $f_{0}(\mathrm{~Hz})$ & 12 & -0.277 & 0.3839 \\
\hline & & & \\
\hline
\end{tabular}




\begin{tabular}{l|l|l|l} 
Time of maximum fo (\%) & 12 & -0.084 & 0.7951 \\
\hline Mean $f_{0}(\mathrm{~Hz})$ & 12 & -0.217 & 0.4978
\end{tabular}

Spearman rho is indicated by $r_{\mathrm{s}}$, and the significances with $p$

\section{Comparison of behavioral responses between focal families and focal pairs}

The global model varied significantly from the null model for PC1 (extreme head up: $\chi^{2}=34.3, d f=9, p=0.0081$ ) and PC3 (head up: $\chi^{2}=109.8, d f=9$, $p<0.0001$ ), and tended to vary for PC2 (comfort behavior: $\chi^{2}=14.7, d f=9$, $p=0.0996$ ). In all final models, the interaction between condition and group membership had an effect on the PC scores (Table 4).

\section{Table 4}

Results of the final LMMs comparing the PC scores of families and pairs

\begin{tabular}{|l|l|l|l|l|}
\hline Coefficients & Estimate & SE & $\begin{array}{c}\boldsymbol{T} \text { Shold be lower case } \\
\text { value }\end{array}$ & $\boldsymbol{p}$ \\
\hline $\begin{array}{l}\text { PC 1 (extreme head up) } \\
\text { Final model }\end{array}$ & & & \\
\hline Intercept & 0.036 & 0.120 & 0.30 & 0.7621 \\
\hline Condition (1 vs. 2) & 0.457 & 0.104 & 4.41 & $<0.0001$ \\
\hline Condition (1 vs. 3) & 0.062 & 0.104 & 0.60 & 0.5480 \\
\hline Condition (2 vs. 3) & -0.395 & 0.104 & -3.81 & 0.0002 \\
\hline Sex (female vs. male) & -0.253 & 0.127 & -1.99 & 0.0512 \\
\hline $\begin{array}{l}\text { Group (families vs. } \\
\text { pairs) }\end{array}$ & -0.054 & 0.161 & -0.34 & 0.7370 \\
\hline Condition (1):group & 0.389 & 0.164 & 2.37 & 0.0182 \\
\hline Condition (2):group & -0.448 & 0.164 & -2.73 & 0.0066 \\
\hline Condition (3):group & -0.059 & 0.164 & -0.36 & 0.7194 \\
\hline PC 2 (comfort behavior) & & & & \\
\hline Final model & & & & \\
\hline
\end{tabular}




\begin{tabular}{|c|c|c|c|c|}
\hline Intercept & -0.295 & 0.149 & -1.98 & 0.0535 \\
\hline Condition (1 vs. 2 ) & 0.011 & 0.068 & 0.16 & 0.8698 \\
\hline Condition (1 vs. 3 ) & 0.106 & 0.068 & 1.56 & 0.1192 \\
\hline Condition (2 vs. 3 ) & 0.095 & 0.068 & 1.40 & 0.1629 \\
\hline Sex (female vs. male) & 0.211 & 0.176 & 1.20 & 0.2376 \\
\hline $\begin{array}{l}\text { Group (families vs. } \\
\text { pairs) }\end{array}$ & 0.203 & 0.190 & 1.07 & 0.2899 \\
\hline Condition (1):group & -0.170 & 0.107 & -1.58 & 0.1144 \\
\hline Condition (2):group & 0.204 & 0.107 & 1.90 & 0.0583 \\
\hline Condition (3):group & 0.034 & 0.107 & 0.32 & 0.7512 \\
\hline \multicolumn{5}{|l|}{ PC 3 (head up) } \\
\hline \multicolumn{5}{|l|}{ Final model } \\
\hline Intercept & -0.141 & 0.124 & -1.14 & 0.2602 \\
\hline Condition (1 vs. 2 ) & 0.809 & 0.088 & 9.15 & $<0.0001$ \\
\hline Condition (1 vs. 3 ) & 0.674 & 0.088 & 7.63 & $<0.0001$ \\
\hline Condition (2 vs. 3 ) & -0.135 & 0.088 & -1.53 & 0.1280 \\
\hline Sex (female vs. male) & 0.019 & 0.138 & 0.14 & 0.8906 \\
\hline $\begin{array}{l}\text { Group (families vs. } \\
\text { pairs) }\end{array}$ & -0.405 & 0.163 & -2.49 & 0.0152 \\
\hline Condition (1):group & 0.168 & 0.140 & 1.20 & 0.2300 \\
\hline Condition (2): group & -0.838 & 0.140 & -5.99 & $<0.0001$ \\
\hline Condition (3):group & -0.670 & 0.140 & -4.79 & $<0.0001$ \\
\hline
\end{tabular}

Pairwise comparisons of coefficients with estimates, standard error (SE), $t$ values, and significance levels are shown. ":" indicate interactions between fixed factors

PC1 (extreme head up) was significantly higher in families as compared to pairs during the playback phase (Estimate $\pm \mathrm{SE}=-0.448 \pm 0.164, t=-2.73$, $p=0.0066)$, and significantly lower in the baseline (Estimate $\pm \mathrm{SE}=0.389 \pm 0.164, t=2.37, p=0.0182$ ), but did not vary in the post-playback phase (Estimate $\pm \mathrm{SE}=-0.059 \pm 0.164, t=-0.36, p=0.7194$; 
Fig. 4).

Fig. 4

Boxplots of estimated mean PC scores of PC 1 (extreme head up) during baseline, playback and post-playback in families and pairs. Values were taken from the final LMM, which controlled for random effects

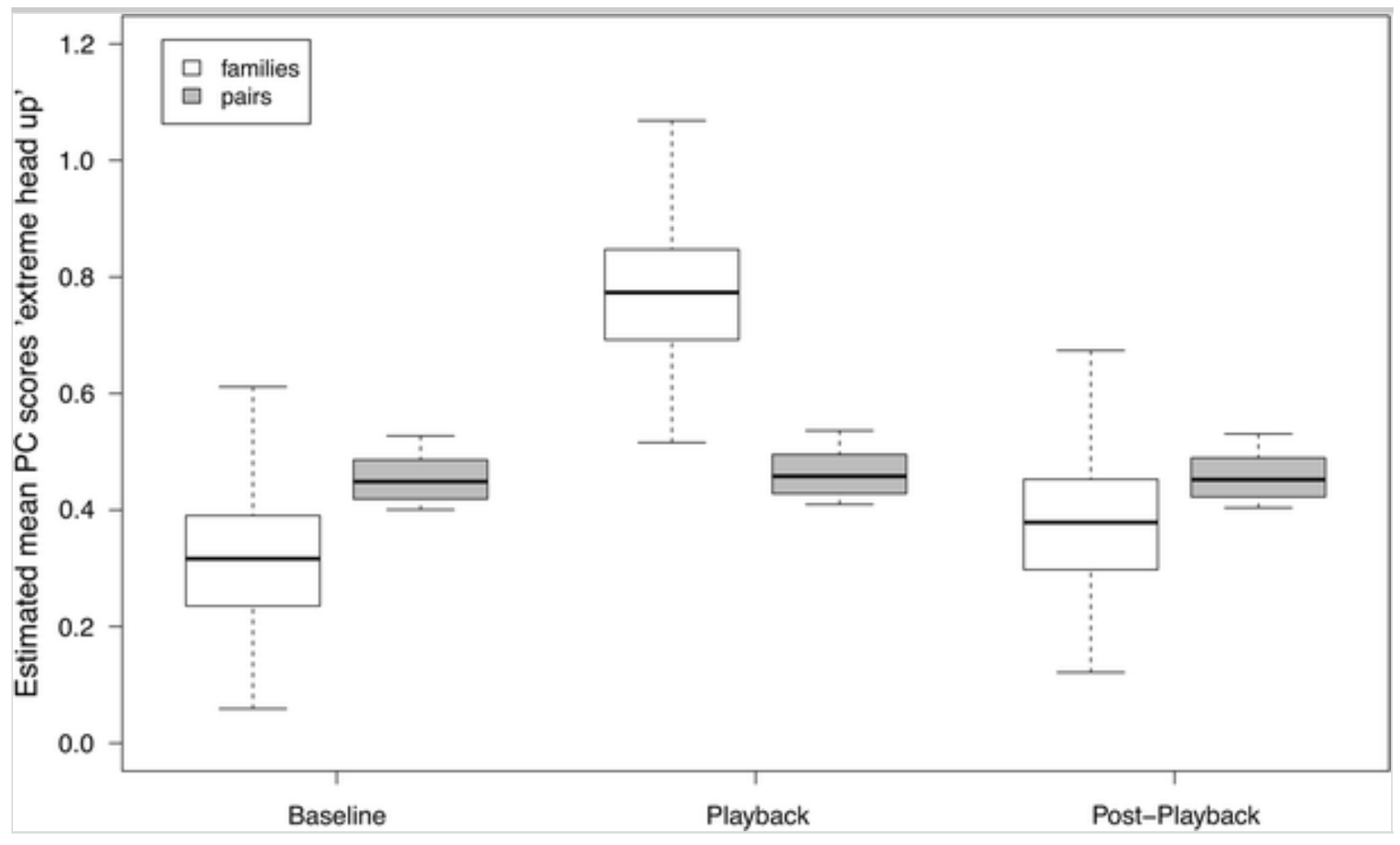

For PC3 (head up), families showed significantly higher scores than pairs during the playback (Estimate $\pm \mathrm{SE}=-0.838 \pm 0.140, \mathrm{t}=-5.99, p<0.0001$ ) and the post-playback phase (Estimate $\pm \mathrm{SE}=-0.670 \pm 0.140, t=-4.79$, $p<0.0001$ ), but not during the baseline phase (Estimate $\pm \mathrm{SE}=0.168 \pm 0.140$, $t=1.20, p=0.2300$; Fig. 5).

\section{Fig. 5}

Mean estimates of scores of PC 3 (head up) in families (white boxes) and pairs (grey boxes) 


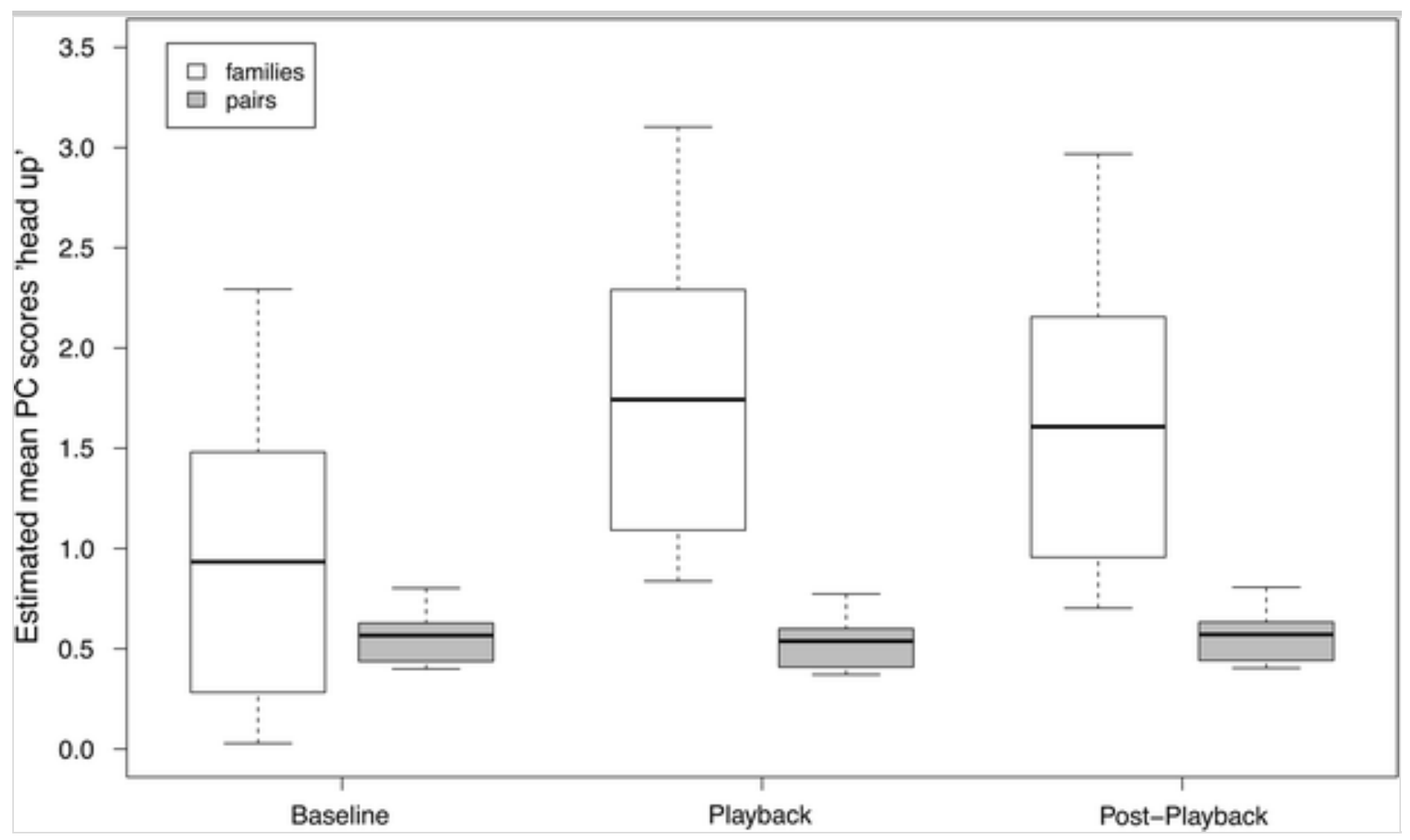

PC2 (comfort behavior) tended to be higher in pairs than in families during the playback presentation (Estimate $\pm \mathrm{SE}=0.204 \pm 0.107, z=1.90, p=0.0583$; Fig. 6), but showed no significant variation in the baseline (Estimate $\pm \mathrm{SE}=-0.170 \pm 0.107, t=-1.58, p=0.1144$ ) and the post-playback phase (Estimate $\pm \mathrm{SE}=0.034 \pm 0.107, t=0.32, p=0.7512)$.

Fig. 6

Estimated mean PC scores for PC 2 (comfort behavior) shown as a response during the three experimental conditions by families and pairs 


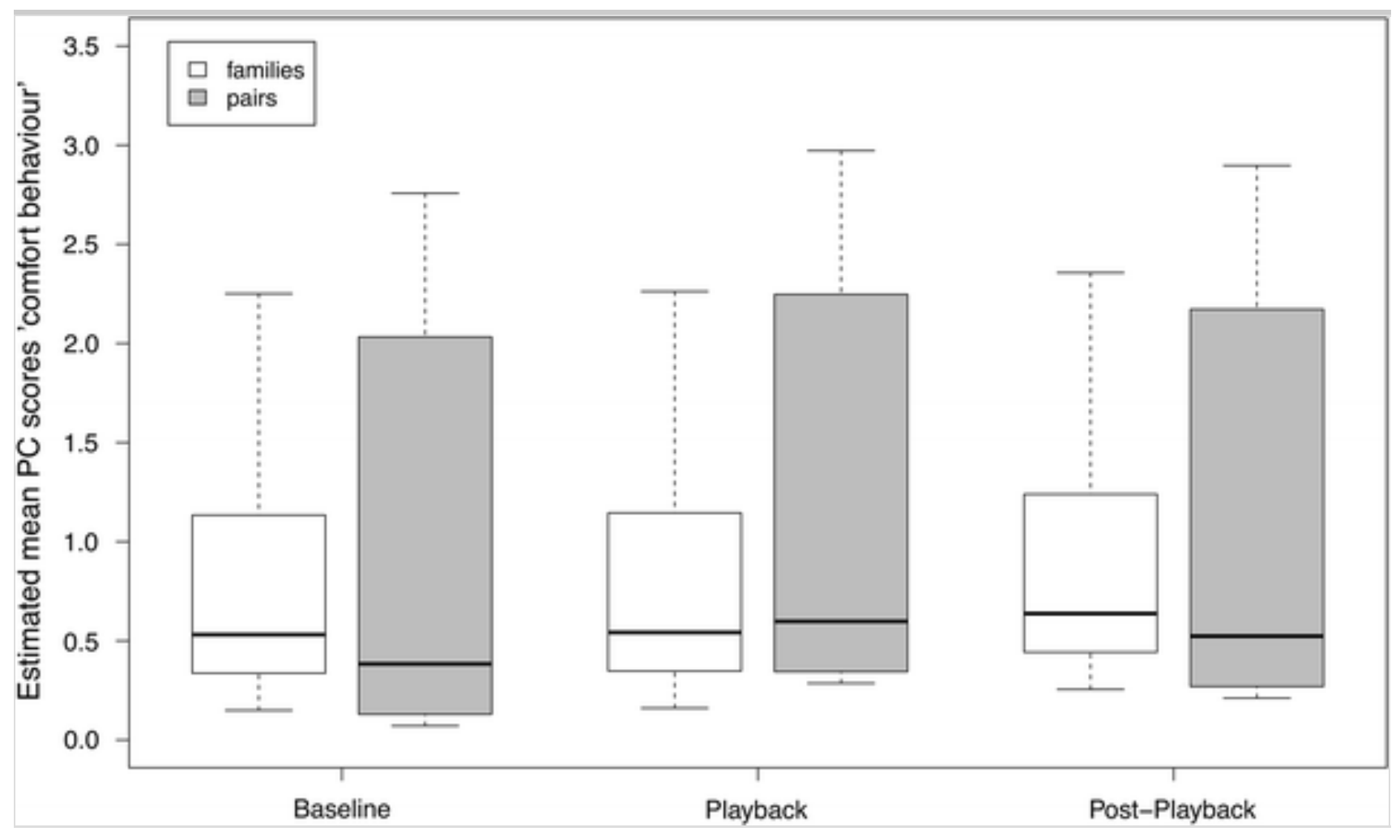

\section{Behavioral responses of focal families}

The null model explained significantly less of the variation of $\operatorname{PC} 1\left(\chi^{2}=21.9\right.$, $d f=10, p=0.0154)$ and PC3 $\left(\chi^{2}=64.7, d f=10, p<0.0001\right)$ than the global model. No difference was found between the global modal and the null model for PC2 $\left(\chi^{2}=12.5, d f=10, p=0.2510\right)$ (Table 5).

\section{Table 5}

Results of the final LMMs of families

\begin{tabular}{|l|l|l|l|l|}
\hline Coefficients & Estimate & SE & $\begin{array}{c}\boldsymbol{T} \text { Should be lower } \\
\text { case " } t \text { " value }\end{array}$ & $\boldsymbol{p}$ \\
\hline PC 1 (extreme head up) & & & \\
\hline Final model & \multicolumn{5}{|l|}{} & & \\
\hline Intercept & -0.181 & 0.405 & -0.45 & 0.6567 \\
\hline Condition (1 vs. 2) & 0.356 & 0.104 & 3.42 & 0.0008 \\
\hline Condition (1 vs. 3) & 0.049 & 0.104 & 0.47 & 0.6418 \\
\hline Condition (2 vs. 3) & -0.307 & 0.104 & -2.95 & 0.0036 \\
\hline
\end{tabular}




\begin{tabular}{|c|c|c|c|c|}
\hline $\begin{array}{l}\text { Familiarity (unfamiliar } \\
\text { vs. familiar) }\end{array}$ & -0.064 & 0.119 & -0.54 & 0.5966 \\
\hline Sex (female vs. male) & -0.330 & 0.161 & -2.05 & 0.0484 \\
\hline Number of goslings & 0.034 & 0.072 & 0.48 & 0.6351 \\
\hline Age goslings & 0.003 & 0.008 & 0.40 & 0.6904 \\
\hline \multicolumn{5}{|l|}{ PC 3 (head up) } \\
\hline \multicolumn{5}{|l|}{ Final model } \\
\hline Intercept & 0.308 & 0.467 & 0.66 & 0.5149 \\
\hline Condition (1 vs. 2) & 0.714 & 0.097 & 7.37 & $<0.0001$ \\
\hline Condition (1 vs. 3 ) & 0.595 & 0.097 & 6.14 & $<0.0001$ \\
\hline Condition (2 vs. 3 ) & -0.119 & 0.097 & -1.23 & 0.2203 \\
\hline $\begin{array}{l}\text { Familiarity (unfamiliar } \\
\text { vs. familiar) }\end{array}$ & -0.003 & 0.083 & -0.03 & 0.9759 \\
\hline Sex (female vs. male) & 0.097 & 0.193 & 0.50 & 0.6212 \\
\hline Number of goslings & 0.211 & 0.085 & 2.49 & 0.0199 \\
\hline Age goslings & -0.026 & 0.009 & -2.86 & 0.0071 \\
\hline
\end{tabular}

PC scores of extreme head up (PC1) and of head up (PC3) were significantly higher during the playback phase as compared to the baseline (PC1:

Estimate $\pm \mathrm{SE}=0.356 \pm 0.104, t=3.42, p=0.0008$; PC3:

Estimate $\pm \mathrm{SE}=0.714 \pm 0.097, t=7.37, p<0.0001$; see Table 5). While scores of PC1 significantly decreased compared to the playback in the post-playback phase (Estimate $\pm \mathrm{SE}=-0.307 \pm 0.104, t=-2.95, p=0.0036)$, PC3 scores stayed high also during the post-playback phase, varying significantly from scores during the baseline phase (Estimate $\pm \mathrm{SE}=0.595 \pm 0.097, t=6.14$, $p<0.0001$ ), but not from scores during the playback phase (Estimate $\pm \mathrm{SE}=-0.119 \pm 0.097, t=-1.23, p=0.2203$ ).

Scores of extreme head up (PC1) also varies significantly with sex (Estimate $\pm \mathrm{SE}=-0.330 \pm 0.161, t=-2.05, p=0.0484$ ), with females 
showing stronger responses than males (Fig. 7). In addition to condition, PC 3 (head up) was significantly influenced by the total number of goslings (Estimate $\pm \mathrm{SE}=0.211 \pm 0.085, t=2.49, p=0.0199)$ and the age of the goslings (Estimate $\pm \mathrm{SE}=-0.026 \pm 0.009, t=-2.86, p=0.0071$ ), with stronger responses when the number of goslings was higher, and when goslings were younger (Fig. 7 Please remove reference to Fig. 7 ).

\section{Fig. 7}

Estimated mean PC scores for PC 1 (extreme head up) in male and female parental geese

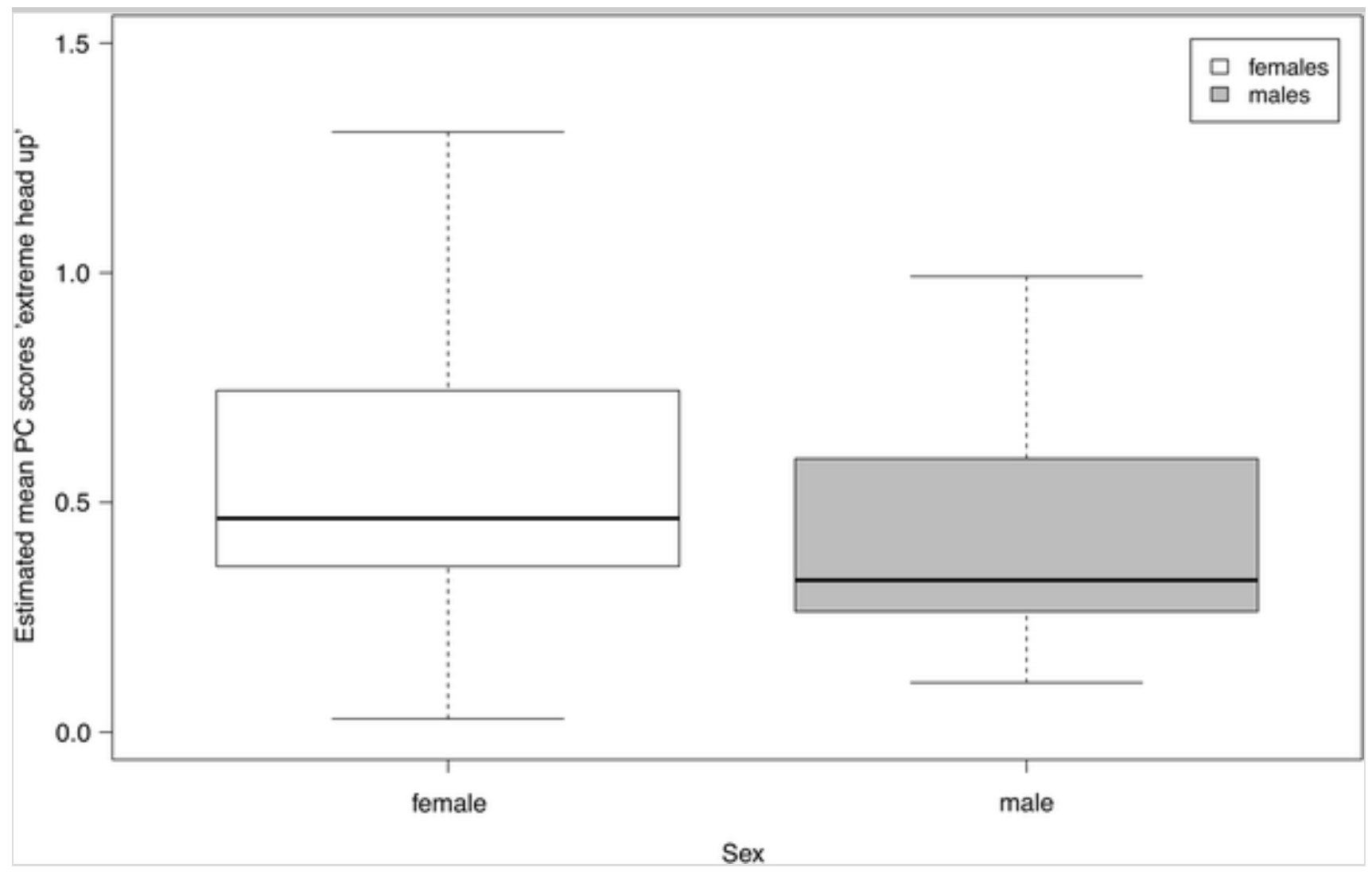

\section{Behavioral responses of focal pairs without offspring}

In pairs without goslings, the global model varied significantly from the null model for extreme head up $\chi^{2}=11.3, d f=5, p=0.0462$ ) and tended to vary for comfort behavior $\left(\chi^{2}=94.1, d f=5, p=0.0937\right)$. No difference was found between the null model and the global model for head up $\left(\chi^{2}=54.3, d f=5\right.$, $p=0.3331)$. 
Extreme head ups increased in the playback phase, with significantly higher scores as compared to the baseline phase (Estimate $\pm \mathrm{SE}=0.323 \pm 0.096$, $t=3.37, p=0.0010$ ), and decreased again significantly in the post-playback phase as compared to the playback phase (Estimate $\pm \mathrm{SE}=-0.202 \pm 0.096$, $t=-2.10, p=0.0373$; Table 6). Comfort behavior also increased significantly during the playback phase as compared to the baseline (Estimate $\pm \mathrm{SE}=0.193 \pm 0.066, t=2.94, p=0.0034$ ), and remained high also in the post-playback phase as compared to the baseline (Estimate $\pm \mathrm{SE}=0.125 \pm 0.066, t=1.91, p=0.0580$ ), and did not vary from scores during the playback phase (Estimate $\pm \mathrm{SE}=-0.067 \pm 0.066, t=-1.02$, $p=0.3078)$.

\section{Table 6}

Results of the final LMMs of pairs without goslings, showing pairwise comparisons of coefficients with estimates, standard error (SE), $t$ values, and significance levels

\begin{tabular}{|c|c|c|c|c|}
\hline Coefficients & Estimate & $\mathbf{S E}$ & $\begin{array}{l}T \text { Should be lower case " } t " \\
\text { value }\end{array}$ & $p$ \\
\hline \multicolumn{5}{|c|}{ PC 1 (extreme head up) } \\
\hline \multicolumn{5}{|l|}{ Final model } \\
\hline Intercept & -0.186 & 0.224 & -0.83 & 0.4158 \\
\hline Condition (1 vs. 2 ) & 0.323 & 0.096 & 3.37 & 0.0010 \\
\hline Condition (1 vs. 3 ) & 0.121 & 0.096 & 1.26 & 0.2089 \\
\hline Condition (2 vs. 3 ) & -0.202 & 0.096 & -2.10 & 0.0373 \\
\hline $\begin{array}{l}\text { Sex (female vs. } \\
\text { male) }\end{array}$ & 0.103 & 0.306 & 0.34 & 0.7402 \\
\hline \multicolumn{5}{|c|}{ PC 2 (comfort behavior) } \\
\hline \multicolumn{5}{|l|}{ Final model } \\
\hline Intercept & -0.136 & 0.243 & -0.56 & 0.5836 \\
\hline Condition (1 vs. 2) & 0.193 & 0.066 & 2.94 & 0.0039 \\
\hline Condition (1 vs. 3 ) & 0.125 & 0.066 & 1.91 & 0.0579 \\
\hline Condition (2 vs. 3 ) & -0.067 & 0.066 & -1.02 & 0.3078 \\
\hline Sex (female vs. & & & & \\
\hline
\end{tabular}




\section{Discussion}

Our results show that adult parental and non-parental Greylag Geese responded differently to gosling distress calls. While focal families responded with increased vigilance, pairs without goslings showed more comfort behavior at and after the presentation of gosling distress calls, instead. Within the families, we found that parental geese were more vigilant when the number of gosling was high and when goslings were young, but we found no indication of kin recognition, as vigilance was increased in response to all distress calls, irrespective of familiarity. Further, parental females responded more strongly to gosling distress calls with extreme head up behavior than their mates.

Our findings do not contradict the well-documented fact that over the entire rearing period from autumn to spring, parental male geese show higher levels of vigilance than their female partners (Black and Owen 1989; Williams et al. 1994), but rather they hint at context-dependent and seasonal differences in vigilance behavior between the sexes. Males were shown to display a higher overall vigilance from October through April (Black and Owen 1989), thereby ensuring family cohesion and access to resources. Parental females in our study responded stronger to acoustic signals that may induce a stressful or dangerous situation for the goslings than their mates. This may reflect a balance between quality and quantity in vigilance behavior. In Greylag Geese only the females incubate, and during this period, they barely feed (Rutschke 1987). The conflict between parental investment in the current offspring and available resources for future offspring is assumed to lead to an investment trade-off (Trivers 1974). Data on Barnacle Geese (Black and Owen 1989) and our own observations in Greylag Geese indicate that females spend indeed longer periods feeding during later stages of rearing to compensate their loss of weight after the goslings had hatched. Therefore, the goslings' distress calls may modulate the efficiency particularly of the females' vigilance behavior.

As the recorded distress calls in this study could not be assigned to goslings individually, only to goslings of different families, we cannot state whether there are individual acoustic characteristics within gosling distress calls. 
Discriminating between kin and non-kin by vocalizations can be crucial in complex social life, and it was already shown in Canada Geese (Cowan 1973). However, we found no family-specific acoustic cues that would have enabled discrimination of Greylag goslings' distress calls at a family level. Therefore, distress calls may not play a crucial role in individual or class-level recognition, but rather function as general vigilance triggers for parents: distress calls are produced in case of isolation or stress (Lamprecht 1977; Lorenz 1988) in order to draw the parents' attention towards a detached gosling and thereby reestablish family cohesion (Thoren and Bergmann 1987). The spatial distance between the sender and the receiver(s) can be important in this case: parental Greylag gGeese and their goslings usually maintain close proximity throughout the goslings' first year, and keep their distance to other families (Lamprecht 1987; Lorenz et al. 1979; Scheiber et al. 2005, b). Hence, every distress call emitted close to the parents at this developmental stage is likely to be perceived as a signal from the own offspring. Therefore, parental geese may have responded similarly to both familiar and unfamiliar distress calls due to the spatial proximity at which the stimuli were presented, irrespectively of the family membership of the sender. However, as gosling calls were recorded prior to the playback experiment, it is possible that families did not recognize their own gosling voice due to developmental changes in the calls. Acoustic properties of the recorded distress calls did not vary with gosling age, although the age varied from 6 to 38 days. Investigations on the vocal development of distress calls in Greylag gGeese showed a slight but constant decrease in maximum $f_{0}$ with increasing age (Thoren and Bergmann 1987): in 5-day-old goslings, maximum fo was $3.8 \mathrm{kHz}$, and decreased to an average $1.9 \mathrm{kHz}$ (range $1.6-2.4 \mathrm{kHz}$ ) at the age of 50 days. The sounds used in the experiments thus may have sounded like distress calls of younger goslings, which on the one hand might have precluded recognition of own goslings, and on the other hand, result in less strong vigilance with increasing age of the goslings, as shown for extreme head ups. Whether parental geese reduce vigilance in general as their offspring grow older, or whether the observed decrease in vigilance was due to the stimuli sounding younger than the own offspring, and thus violating the expectancy of the parents, still needs to be investigated in more detail. It is known that expectancy violation may manifest in behaviors such as looking time, which was here measured as duration of vigilance stages. Furthermore, as goslings were not separated from their parents during the playbacks, hearing 
distress calls while their offspring was present may have added to the violation of the parents' expectancy.

In general, we would expect that a potential stressor that causes any gosling to call can easily affect the own offspring as well as oneself, and responding with vigilance should be is beneficial in any case. Our interpretation of gosling distress calls as general facilitators of arousal is supported by the response to distress calls of goslings by non-parental geese (focal pairs). In pairs without goslings we also found an increase in vigilance behavior, however less distinct than in families. Pairs showed increased comfort behavior during and after the playbacks, which is commonly considered an indication of internal conflict and increasing stress levels (“displacement behavior"; (Tinbergen 1952). Studies on heart rate during and after agonistic encounters in Greylag $g$ To be consistent, in "Greylag Geese", Geese should be written with a capital "G" Geese (i.e. conflict situations) showed indeed a correlation between self-directed behaviors such as shaking and auto-grooming and autonomic arousal after conflict situations (Wascher et al. 2010). In primates, self-directed behaviors/auto-grooming also indicated individual emotional tension (Maestripieri et al. 1992), providing insight into an individual's evaluation of a certain event (Aureli and Yates 2010; Castles et al. 1999; Kutsukake 2006). Thus, our results suggest that goose pairs perceived the goslings' distress calls as stressful and alerting, and therefore responded with increased comfort behavior.

In sum, our results indicate that female parental Greylag Geese invest more in vigilance behavior during the early rearing period than their mates in response to distress calls of goslings. Although this may be interpreted as asymmetrical investment between males and females, in the socially monogamous geese, our results could also point to the fact that investment of the sexes may be directed towards different components of fitness. While females invest more in guarding the offspring during early developmental stages, males may invest more in general vigilance towards the social environment in the flock, in mate guarding, and in providing the family with priority access to food during later stages of rearing.

\section{Acknowledgements}

Sincere thanks are given to all the helping hands and people backstage who 
always make the difference between success and failure. In particular: Josef Hemetsberger for being the KLF's constant source of goose wisdom, Gustav Meibauer for scaring away all disturbing subjects from the playback setup, and everyone who ever helped carrying the equipment. We thank Roger Mundry for providing the script for pDFA analysis. We also thank two anonymous referees for their valuable comments that improved the manuscript. For the permanent financial support of the Konrad Lorenz-Research Station we would like to thank the "Herzog von Cumberland Stiftung" and the "Verein der Förderer der Konrad Lorenz Forschungsstelle". GS received funding by the Austrian Science Fund (FWF) projects Y-366-B17 and W-1234-G17. AL was funded by the Austrian Federal Ministry of Science, Research and Economy (BMWFW, former BMWF) project SPA/03-005/Graugänse and DF by the Austrian Science Fund (FWF) project P-21489-B17.

\section{Electronic supplementary material}

Below is the link to the electronic supplementary material.

Supplementary material $1(\mathrm{mp} 325 \mathrm{~kb})$

\section{References}

Aureli F, Yates K (2010) Distress prevention by grooming others in crested black macaques. Biol Lett 6:27-29. https://doi.org/10.1098/rsbl.2009.0513

Barr DJ, Levy R, Scheepers C, Tily HJ (2013) Random effects structure for confirmatory hypothesis testing: keep it maximal. J Mem Lang 68:255-278

Bartoń K (2009) MuMIn: multi-model inference. R package

Bates D, Maechler M, Bolker B, Walker S (2015) Fitting linear mixedeffects models using lme4. J Stat Softw 67:1-48. https://doi.org/10.18637/jss.v067.i01

Beecher M (1988) Kin recognition in birds. Behav Genet 18:465-482. 
https://doi.org/10.1007/bf01065515

Bermant $\mathrm{G}$ (1963) Intensity and rate of distress calling in chicks as a function of social contact. Anim Behav 11:514-517

Bernaards CA, Jennrich RI (2005) Gradient projection algorithms and software for arbitrary rotation criteria in factor analysis. Educ Psychol Meas 65:676-696

Black JM (1988) Preflight signalling in swans: a mechanism for group cohesion and flock formation. Ethology 79:143-157.

https://doi.org/10.1111/j.1439-0310.1988.tb00707.x

Black JM, Owen M (1989) Parent-offspring relationships in wintering barnacle geese. Anim Behav 37(2):187-198. https://doi.org/10.1016/00033472(89)90109-7

Block SA (2013) Gosling survival in Greylag Geese: effects of parental behaviour, previous breeding experience and family movements. Master thesis, Eberhard Karls Universität Tübingen (69 pages)

Branch CL, Freeberg TM (2012) Distress calls in tufted titmice (Baeolophus bicolor): are conspecifics or predators the target? Behav Ecol 23:854-862. https://doi.org/10.1093/beheco/ars041

Caraco T (1980) Stochastic dynamics of avian foraging flocks. Am Nat $115: 262-275$

Castles DL, Whiten A, Aureli F (1999) Social anxiety, relationships and selfdirected behaviour among wild female olive baboons. Anim Behav 58:12071215. https://doi.org/10.1006/anbe.1999.1250

Chaiken M (1992) Individual recognition of nestling distress screams by European starlings (Sturnus vulgaris). Behaviour 120:139-150. https://doi.org/10.2307/4535002

Cowan PJ (1973) Parental calls and the approach behavior of young Canada 
geese: a laboratory study. Can J Zool 51:647-650.

https://doi.org/10.1139/z73-095

Ebbinge BS (1985) Factors determining the population size of arcticbreeding geese, wintering in Western Europe. Ardea 73:1-128

Fichtel C, Manser MB (2010) Vocal communication in social groups. In: Kappeler P (ed) Animal behaviour: evolution and mechanisms. Springer, Heidelberg, pp 29-54

Frigerio D, Weiss BM, Kotrschal K (2001) Spatial proximity among adult siblings in Greylag geese (Anser anser): evidence for female bonding? Acta ethol 3:121-125. https://doi.org/10.1007/s102110000028

Hemetsberger J (2001) Die Entwicklung der Grünauer Graugansschar seit, 1973. In: Kotrschal K, Müller G, Winkler H (eds) Konzepte der Verhaltensforschung. Konrad Lorenz und die Folgen. Filander-Verlag, Fürth, pp 249-260

Hirschenhauser K (2012) Testosterone and partner compatibility: evidence and emerging questions. Ethology 118:799-811.

https://doi.org/10.1111/j.1439-0310.2012.02087.x

Janik VM, Slater PJB (1998) Context-specific use suggests that bottlenose dolphin signature whistles are cohesion calls. Anim Behav 56:829-838. https://doi.org/10.1006/anbe.1998.0881

Johnsgard PA (1965) Observations on some abberant Australian Anatidae. Wildfowl 16:73-83

Kutsukake N (2006) The context and quality of social relationships affect vigilance behaviour in wild chimpanzees. Ethology 112:581-591. https://doi.org/10.1111/j.1439-0310.2006.01200.x

Lamprecht J (1977) A comparison of the attachment to parents and siblings in juvenile geese (Branta canadensis and Anser indicus): reactions to brief separation. Ethology 43:415-424. https://doi.org/10.1111/j.1439- 
Lamprecht J (1987) Female reproductive strategies in bar-headed geese (Anser indicus): why are geese monogamous? Behav Ecol Sociobiol 21:297305. https://doi.org/10.1007/bf00299967

Lazarus J, Inglis IR (1978) The breeding behaviour of the pink-footed goose: parental care and vigilant behaviour during the fledging period. Behaviour 65:62-87. https://doi.org/10.1163/156853978X00198

Ligon DJ (1999) The evolution of avian breeding systems. Oxford University Press, Oxford

Lingle S, Wyman MT, Kotrba R et al (2012) What makes a cry a cry? A review of infant distress vocalizations. Curr Zool 58:698-726

Lorenz K (1988) Hier bin ich—wo bist du? Ethologie der Graugans. Piper Verlag, München

Lorenz K, Kalas S, Kalas K (1979) Das Jahr der Graugans. Piper Verlag, München

Maestripieri D, Schino G, Aureli F, Troisi A (1992) A modest proposal: displacement activities as an indicator of emotions in primates. Anim Behav 44:967-979. https://doi.org/10.1016/S0003-3472(05)80592-5

Marler P (2004) Bird calls: a cornucopia for communication. In: Marler P, Slabbekoorn H (eds) Nature's Music. Elsevier Academic Press, London, pp $132-178$

Maynard Smith J (1977) Parental investment: a prospective analysis. Anim Behav 25:1-9. https://doi.org/10.1016/0003-3472(77)90062-8

Mundry R, Sommer C (2007) Discriminant function analysis with nonindependent data: consequences and an alternative. Anim Behav 74:965976. https://doi.org/10.1016/j.anbehav.2006.12.028 
Owen M (1982) Population dynamics of Svalbard barnacle geese 19701980. The rate, pattern and causes of mortality as determined by individual marking. Aquila 89:229-247

Pflüger FJ, Fichtel C (2012) On the function of redfronted lemur's close calls. Anim Cogn 15:823-831. https://doi.org/10.1007/s10071-012-0507-9

R Core Team (2017) R: A language and environment for statistical computing. R Foundation for Statistical Computing, Vienna, Austria. URL https://www.R-project.org/

Radesäter T (1976) Individual sibling recognition in juvenile Canada geese (Branta canadensis). Can J Zool 54:1069-1072. https://doi.org/10.1139/z76121

Revelle W (2017) psych: procedures for personality and psychological research. Northwestern University, Evanston

Rutschke EWR (1986) Paar- und Familienzusammenhalt bei der Graugans (Anser anser L.). Wissenschaftliche Zeitschrift der Humboldt-Universität zu Berlin 35:246-253

Rutschke E (1987) Die Wildgänse Europas: Biologie, Ökologie, Verhalten. Aula Verlag, Wiesbaden

Scheiber IBR, Weiss BM, Frigerio D, Kotrschal K (2005) Active and passive social support in families of Greylag geese (Anser anser). Behaviour 142:1535-1557

Scheiber IBR, Kotrschal K, Weiss BM (2009a) Benefits of family reunions: social support in secondary Greylag goose families. Horm Behav 55:133138. https://doi.org/10.1016/j.yhbeh.2008.09.006

Scheiber IBR, Kotrschal K, Weiss BM (2009b) Serial agonistic attacks by Greylag goose families, Anser anser, against the same opponent. Anim Behav 77:1211-1216. https://doi.org/10.1016/j.anbehav.2009.01.026 
Sharp SP, McGowan A, Wood MJ, Hatchwell BJ (2005) Learned kin recognition cues in a social bird. Nature 434:1127-1130.

https://doi.org/10.1038/nature03522

ten Thoren A, Bergmann H-H (1987) Die Entwicklung der Lautäußerungen bei der Graugans (Anser anser). J Ornithol 128:181-207.

https://doi.org/10.1007/bf01661695

Tibbetts EA, Dale J (2007) Individual recognition: it is good to be different. Trends Ecol Evol 22:529-537

Tinbergen N (1952) "Derived" activities; Their causation, biological significance, origin, and emancipation during evolution. Q Rev Biol 27:1-32

Trivers RL (1974) Parent-offspring conflict. Am Zool 14:249-264

Wade MJ, Shuster SM (2002) The evolution of parental care in the context of sexual selection: a critical reassessment of parental investment theory. Am Nat 160:285-292

Wascher CAF, Arnold W, Kotrschal K (2008) Heart rate modulation by social contexts in Greylag geese (Anser anser). J Comp Psychol 122:100107. https://doi.org/10.1037/0735-7036.122.1.100

Wascher CAF, Fraser ON, Kotrschal K (2010) Heart rate during conflicts predicts post-conflict stress-related behavior in Greylag geese. PLoS One 5:e15751

Weiss BM, Kotrschal K, Möstl E, Hirschenhauser K (2010) Social and lifehistory correlates of hormonal partner compatibility in Greylag geese (Anser anser). Behav Ecol 21:138-143. https://doi.org/10.1093/beheco/arp164

Williams TD, Loonen MJ, Cooke F (1994) Fitness consequences of parental behavior in relation to offspring number in a precocial species: the Lesser Snow goose. Auk 111:563-572

Zuur A, Ieno EN, Walker N et al (2009) Mixed effects models and 
extensions in ecology with R. In: Gail M, Krickeberg K, Samet JM et al (eds) Statistics for biology and health. Springer, New York, pp 261-294 